\title{
Retorno econômico da citricultura versus cultivo de grãos na região de Paranapanema - SP
}

Economic return of citrus cultivation versus grain cultivation in the Paranapanema-SP region

\author{
Thiago da Rocha Ribeiro ${ }^{1 * ;}$ Mônica Regina Franco ${ }^{2}$
}

${ }^{1}$ Bacharel em Administração de Empresas - Rua das Carnaúbas, 275 - Campos de Holambra - CEP 18.725-000 - Paranapanema (SP), Brasil<thiagorocha5@gmail.com>

${ }^{2}$ ESALQ/USP - Doutorando em Genética e Melhoramento de Plantas - Av. Pádua Dias, 11 - Departamento de Genética - Bairro Agronomia - CEP 13418-900 - Piracicaba (SP), Brasil

\section{Resumo}

Diante do atual cenário da economia brasileira, a agricultura tem se mostrado atrativa e sustentável, principalmente quando comparada a outros setores, incentivando novos investimentos no ramo. Mas, tanto para produtores tradicionais quanto para investidores iniciantes, há uma variedade enorme de culturas e sistemas de produção à disposição. Nesse contexto, a região de Paranapanema, no estado de São Paulo, é destaque na produção irrigada de grãos, e sua citricultura está em constante crescimento. Sendo assim, este trabalho buscou avaliar e comparar o retorno econômico da citricultura com a rotação de culturas irrigadas de grãos. Os parâmetros utilizados foram Valor presente líquido [VPL], Taxa interna de retorno [TIR], Valor Uniforme Líquido [VUL], Índice de Lucratividade [IL] e Payback Descontado. Para avaliação dos riscos foi utilizada avaliação estatística de números aleatórios gerados através do método de Monte Carlo. Os dados resultantes apresentaram que a cultura de laranja obteve VPL projetado de R $\$ 2.625 .495,12$, com $2,87 \%$ de probabilidade do mesmo ser negativo. Enquanto que o cultivo de grãos apresentou VPL de R\$ 902.977,92, com 7,05\% de chance de resultar em valor presente líquido negativo. Apesar das baixas probabilidades em obter-se $\mathrm{VPL}<0$, ainda existe o risco de que os empreendimentos apresentem fluxos intermediários negativos, e que o produtor seja obrigado a recorrer a reservas de recursos ou captação por meio do crédito rural, ambas alternativas gerando impactos no resultado final. Diante do exposto, apesar de ambos os projetos serem viáveis, a citricultura demonstrou fornecer maior retorno econômico ao produtor rural.

Palavras-chave: avaliação de projetos, monte carlo, retorno econômico, taxa interna de retorno, valor presente líquido

\begin{abstract}
In the face of the current economic outlook in Brazil, agriculture has proven itself as attractive and sustainable, especially if compared to other sectors, promoting new investments in the field. However, there is a huge variety of crops and farming systems available, either for traditional farmers or beginner investors. In such context, the region of Paranapanema in the State of São Paulo is a highlight in the irrigated grain production, and its citrus fruits production has been constantly growing. Thus, this paper aims at assessing and comparing the economic return of the citrus business to the cycle of irrigated grain crops. Net Present Value [NPV], Internal Rate of Return [IRR], Net Uniform Series, Profitability Index [PI] and Discounted Payback were used as parameters. For risk assessment, the statistical evaluation of numbers randomly generated by Monte Carlo method was used. The resulting data shows that orange crops have achieved R\$ 2.625.495,12 of forecasted NPV, with 2,87\% probability of being negative, while grain crops presented R\$ $902.977,92$ of NPV, with 7,05\% chances of resulting in negative net present value. Despite low probabilities of achieving NPV $<0$, there is still the risk that businesses might present negative intermediate consumption flow and the farmer is required to turn to funds reservation or rural credit. Both alternatives could affect the results. Based on the above considerations, despite both projects being feasible, citrus fruits production has proven to be capable of providing better economic return for farmers.
\end{abstract}

Keywords: Project Assessment, Monte Carlo, Net Present Value, Internal Rate of Return

\section{Introdução}

O constante crescimento da população mundial, projetada dos 7,3 bilhões de pessoas em 2016, para 9,7 bilhões em 2050 e 11,2 bilhões em 2100, aliado a escassez mundial de fatores de produção como água e solos agricultáveis, somados com desastres naturais e urbanização, tornarão a demanda mundial por alimentos cada vez maior, e colocarão o Brasil numa posição de destaque, não somente como importante player comercial, mas também como um dos principais 
responsáveis pela segurança alimentar do planeta (UNRIC, 2015; FAO, 2016).

A agricultura brasileira se mostra bem variada, em consequência das condições climáticas diversificadas, produzindo culturas tanto de clima temperado quanto tropical, e cresceu aproximadamente $6,5 \%$ ao ano, de 1990 a 2013 (OCDE-FAO, 2015).

O crescimento acima citado foi apoiado pelo aumento constante da eficiência na utilização de fatores de produção, mecanização rápida, substituição de maquinário obsoleto, investimentos em pesquisas para agricultura em clima tropical, tecnologias de fixação de nitrogênio, sistema de plantio direto e novas variedades de grãos adaptadas ao clima brasileiro (OCDE-FAO, 2015).

A produção brasileira de grãos evoluiu de 57 milhões de toneladas, colhidas em uma área de 37 milhões de hectares, na safra 90/91, para 207 milhões de toneladas, em 57 milhões de hectares, na safra 2014/15. Fazendo com que a relação, tonelada de grãos colhidos por hectare cultivado, saísse de 1,54 para 3,63, reforçando a evolução tecnológica e aumento da rentabilidade das lavouras do país (CONAB, 2016a, b).

Do total dessa produção, a soja possui $47 \%$ de participação e o milho $40 \%$, além de terem respondido juntas por $96 \%$ das exportações brasileiras de grãos na safra 2014/15, gerando importantes resultados na balança comercial do país. Por sua vez, o feijão possui um mercado predominantemente interno, com produção levemente abaixo do consumo, e o trigo encontra-se em situação de maior dependência de importação, com uma produção de $55 \%$ do consumo interno na safra 2014/15 (CONAB, 2016a).

Também em posição de destaque, a citricultura é uma das mais importantes agroindústrias brasileiras, responsável por $60 \%$ da produção mundial de suco de laranja, tornando o país autossuficiente e líder mundial na produção e exportação do produto (MAPA, 2016).

A laranja foi introduzida no Brasil em 1501, trazida da Espanha pelos portugueses, e, desde então, a cultura evoluiu, passando por vários estados até se concentrar no estado São Paulo, e, gerou mais de US\$ 50 bilhões em divisas para o país (Neves et al., 2007).

Os principais importadores mundiais de suco de laranja, representando 85\% das compras, são Estados Unidos, União Européia e Canadá, sendo a segunda o principal destino das exportações brasileiras, e aumentando o percentual anualmente (MAPA, 2016).

No município de Paranapanema - SP, a cultura de laranja ainda tem pouca representatividade se comparada às culturas de grãos. No ano de 2015 , a área colhida da fruta foi de 990 hectares enquanto que a área colhida de soja, principal grão produzido, foi de 12.000 hectares (SIDRA-IBGE, 2016). Porém, a área ocupada com laranja vem aumentando ano após ano, com produtores sendo atraídos por boas condições de produção e melhores preços após a forte crise que atingiu o setor de 2012 à 2015.

Tendo em vista o novo cenário de crescimento da área do cultivo de laranja, julga-se importante analisar a viabilidade e os retornos econômicos da mesma, comparando-os aos de grãos como soja, milho, trigo e feijão, plantados em rotação de culturas no sistema de plantio direto (práticas amplamente difundidas no município), gerando informações que podem ser utilizadas tanto por produtores tradicionais da região, quanto por potenciais investidores do agronegócio.

Diante do exposto, o presente trabalho teve como objetivo analisar a viabilidade econômica da ocupação de área produtiva com citricultura e compará-la ao cultivo de grãos.

\section{Material e Métodos}

\section{Região e premissas da pesquisa}

O trabalho foi realizado no município de Paranapanema - SP, que possui população estimada (ano 2016) de 19.545 mil habitantes, com área total de 1.018.724 $\mathrm{km}^{2}$, altitude de 600 metros, temperatura média anual de $21^{\circ} \mathrm{C}$ e precipitação média anual de 1.407 mm (CEPAGRI, 2016; IBGE, 2016).

Considerou-se a implantação dos empreendimentos em uma área arrendada hipotética de 100 hectares, antes ocupada com pastagem de baixo rendimento. Verificando qual das duas atividades agrícolas propicia maior retorno econômico para o agricultor, através de métodos de avaliação de projetos como Payback descontado, Taxa interna de retorno [TIR] e Valor Presente Líquido [VPL].

Foi elaborada pesquisa com produtores rurais, agrônomos e na cooperativa de produtores rurais local, sobre a forma de cultivo das lavouras irrigadas de grãos no município, apurando-se épocas de plantio, sistema de rotação de culturas e vazio sanitário, para construção de um plano de plantio ideal, contendo soja, milho safrinha, trigo e feijão, no período de cinco anos.

O plano acima citado consiste em dividir a área de 100 hectares irrigados por pivô central em duas partes iguais, sendo chamadas de área A e área B. A partir do primeiro ano safra, na área $A$, executa-se o plantio de feijão em julho do $1^{\circ}$ ano, soja em novembro do $1^{\circ}$ ano e trigo em maio do $2^{\circ}$ ano. $\mathrm{Na}$ área $\mathrm{B}$, plantio de soja em setembro do $1^{\circ}$ ano, seguido de milho safrinha em fevereiro do $2^{\circ}$ ano. Deste ponto em diante, os cronogramas se invertem entre as áreas $\mathrm{A}$ e $\mathrm{B}$, permitindo que haja o mesmo tamanho de área plantada de cada cultura, sendo 100 hectares de soja e 50 hectares das demais lavouras.

Para o empreendimento da laranja foi considerado pomar contendo as variedades precoces (Westin, Rubi e Hamlin), de meia estação (Pera-rio) e tardias (Valência, Natal e Folha murcha). Plantadas com espaçamento de 6 metros entre ruas e 2 metros entre plantas, resultando em 833 plantas por hectare. 


\section{Investimentos, preços, custos e tributação}

Foram feitos levantamentos, com cinco produtores rurais do município e na cooperativa local, de todos os custos fixos (funcionários, seguros, despesas de administração, etc.) e variáveis, desembolsáveis ou não, histórico de produtividades, investimentos iniciais em capital não circulante (máquinas, correção de solo, etc.), custo com arrendamento e necessidade de capital de giro de todas as atividades analisadas no trabalho, dividindose em (a) plano de plantios sucessivos de soja, milho safrinha, trigo, feijão e (b) o pomar de laranja.

As médias de preços para grãos (soja, milho, trigo e feijão), no município de Avaré - SP (localidade mais próxima de Paranapanema com cotações disponíveis), foram obtidas por meio do site Agrolink (2016), abrangendo os últimos cinco anos, nos quatro meses seguintes à colheita, pois marcam o período de maior comercialização de cada produto. Posteriormente, os dados foram deflacionados pelo Índice Geral de Preços Disponibilidade Interna [IGP-DI] da Fundação Getúlio Vargas, recorrendo a "Calculadora do Cidadão", disponível no site do Banco Central do Brasil (2016). Gerando assim, a base de dados para cálculo dos preços médios, considerados constantes no fluxo real de caixa do projeto.

Para a laranja, a média de preço foi observada no site do Centro de Estudos Avançados em Economia aplicada - CEPEA (2016) da ESALQ/USP, a partir da série "Laranja posta na indústria Paulista (sem contrato)", que representa preços à vista (mercado "spot", sem contrato com indústrias de suco), e atualizada pelo mesmo índice e método das séries dos grãos, citados anteriormente.

Importante ressaltar que, nesta pesquisa, foi considerado que todas as séries históricas de preços, dos cinco produtos analisados, possuem distribuição normal, e não foram efetuados testes de normalidade dos dados como, por exemplo, Teste Anderson-Darling, Teste Shapiro-Wilk, Teste Lilliefors, entre outros.

A tributação considerada nos projetos foi a mesma aplicada aos produtores rurais pessoas físicas que produzem as culturas estudadas. Resumindo-se a 2,3\%, recolhido sobre o valor bruto das vendas, ao Fundo de Assistência ao Trabalhador Rural [Funrural], Riscos Ambientais de Trabalho [RAT] e ao Serviço Nacional de Aprendizagem Rural [SENAR]; e ao Imposto sobre a Renda da atividade rural da Pessoa física, tributado pelo Lucro real e calculado conforme tabela progressiva anual a partir de 2017, ano calendário 2016, disponível no site da Receita Federal do Brasil (2016).

$\mathrm{Na}$ apuração do resultado da atividade rural para fins de imposto de renda, foi considerada a instrução normativa $n^{\circ} 83$ da Receita Federal do Brasil (2001). Destacando, entre outros procedimentos, o lançamento das despesas com investimento (plantio, compra de máquinas, e etc.) e custeio no cálculo do resultado anual. Possibilitando ao produtor que investir em qualquer um dos dois projetos, compensar os prejuízos contábeis obtidos em determinado ano (geralmente nos primeiros anos após o plantio) com o lucro de exercícios posteriores, resultando em menor despesa de imposto de renda.

\section{Provisões de recursos}

Segundo Simões et al. (2015), a cultura de laranja começa a produzir, de forma crescente, no terceiro ano após o plantio. Isso implica na necessidade de investimentos para manter o pomar do primeiro ao terceiro ano e de um capital de giro médio a ser utilizado a partir do quarto ano. Além disso, as máquinas adquiridas no início do projeto têm vida útil prevista de 10 anos, o que gera a necessidade de investimento em um novo parque de máquinas no décimo ano.

Apesar do retorno (VPL) com citricultura possa ser considerado mais alto em comparação à outras culturas, deve ser levado em conta a necessidade de aportes de capital adicionais (provisão) para gerenciar riscos de fluxos de caixa negativos durante a execução do projeto e risco de VPL negativo. Ou seja, a provisão de recursos faz-se necessária quando um projeto com expectativa de VPL positivo apresenta risco de deficiência de caixa ou de VPL negativo durante a execução, devendo ser aplicada em alternativa sem risco e com rendimento igual ao custo de oportunidade (Adami, 2010) ${ }^{1}$.

Sendo assim, além dos investimentos no momento inicial, aqueles que serão aplicados em momentos posteriores (anos 1, 2, 3, 4 e 10) foram trazidos a valor presente pelo custo real de oportunidade de aplicação financeira em Letra de crédito do Agronegócio [LCA], e provisionados no ano zero, para que possam ser aplicados na referida letra e resgatados de acordo com o cronograma. Caso o fluxo de caixa de determinado ano seja suficiente para amparar os novos investimentos, a aplicação não será resgatada, sendo atualizada financeiramente até o fim do projeto e retornará como recuperação de capital no ano 20.

Para os grãos foi adotado o mesmo procedimento acima, com provisionamento de recursos apenas para a troca do parque de máquinas no décimo ano, visto que a atividade gera caixa suficiente já no primeiro ano.

Além da provisão para investimentos citada, com base nos custos variáveis iniciais (antes da colheita e comercialização) e os custos fixos desembolsáveis, foi calculada a necessidade ponderada de capital de giro de ambos os projetos, e computada no investimento inicial, com retorno previsto no último ano.

Dessa forma, os fluxos de cada projeto se tornaram de fácil comparação, uma vez que refletem investimento inicial na implantação, seguido de fluxos maiores ou

${ }^{1}$ Adami, A.C.O. 2010. Risco e retorno de investimento em citros no Brasil. Tese de Doutorado em Ciências. Escola Superior de Agricultura "Luiz de Queiroz", Universidade de São Paulo, Piracicaba, SP, Brasil. Disponível em: < http://www.teses.usp.br/teses/disponiveis/11/11132/tde-24052010110330/pt-br.php>. Acesso em: 01 set 2016 
iguais a zero nos próximos anos, e permitindo ao investidor o conhecimento de quanto de capital, a valores presentes, deverá aplicar em cada um dos projetos.

\section{Construção do Fluxo de caixa}

Adequando-se à prática do mercado agrícola, para este trabalho, a medida de tempo considerada foi ano safra (início em julho do primeiro ano e término em junho do segundo), ou seja, no desenvolvimento do fluxo de caixa detalhado a seguir, foi considerado ano safra, ou ano agrícola, e não ano do calendário civil.

Para a montagem dos fluxos de ambos os empreendimentos, de modo a atender o objetivo de avaliar exclusivamente retornos econômicos, foram desconsiderados ganhos de sinergia e de escala entre diversos recursos da atividade rural, e outros benefícios que o produtor rural tradicional pode obter aumentando sua área de produção, e considerado um investidor que deseja entrar em uma das duas atividades estudadas, arrendando uma área de 100 hectares para implantação de um dos dois projetos com recursos próprios.

Levando-se em consideração a perenidade de um pomar de laranja, optou-se por comparar as viabilidades de ambos os empreendimentos em um período de 20 anos. Sendo, o pomar de laranja implantado e mantido dentro desse período, e o plano de plantio das culturas de grãos executado em quatro períodos de cinco anos consecutivos, permitindo assim a comparação no mesmo horizonte de tempo.

Com os dados e premissas acima, foi montado o fluxo real de caixa (desconsiderando o impacto da inflação) de cada empreendimento e calculou-se os indicadores de VPL, TIR, Valor Uniforme Líquido [VUL], Índice de Lucratividade [IL] e Payback descontado.

\section{Taxa mínima de atratividade}

A Taxa Mínima de Atratividade, também conhecida como Taxa Requerida, é a taxa que representa o mínimo de rendimento que o investidor exige obter para aceitar o projeto. Importante ressaltar que, para este trabalho, foi adotado o método de definição de taxa descrito por Lapponi (2007), que considera que o capital investido deve ser remunerado não só pelo valor do dinheiro no tempo (representado pela melhor alternativa "livre" de risco à disposição do investidor) somado à inflação esperada, mas também por um prêmio pelo risco de se aplicar no projeto.

Para remunerar o dinheiro no tempo foi considerada a aplicação em Letra de Crédito do Agronegócio [LCA], remunerada por $78 \%$ da variação do Certificado de Depósito Interbancário [CDI], considerada a melhor aplicação ao alcance do produtor rural investidor. Buscando obter o rendimento esperado da aplicação, calculou-se a variação, anualizada, de 78\% do CDI nos últimos 20 anos (setembro de 1996 a agosto de 2016), por meio da "Calculadora do Cidadão" chegando ao resultado de $12,12 \%$ ao ano de taxa nominal (inflação embutida), considerada na pesquisa.

A inflação esperada considerada no projeto foi obtida a partir da variação anualizada dos últimos 20 anos (agosto de 1996 a setembro de 2016), do IGP-DI da Fundação Getúlio Vargas, também obtida por meio da "Calculadora do Cidadão", resultando em 8,25\% ao ano.

Considerando as avaliações através de fluxos reais de caixa, e conforme o método detalhado em Lapponi (2007), para este trabalho foi escolhida uma TMA real de $6 \%$ ao ano. Taxa essa que foi composta pela remuneração real de 3,58\% (Taxa nominal da LCA descontando a inflação esperada) somada a um prêmio de 2,34\% pelo risco de se aplicar no projeto.

\section{Indicadores de análise e avaliação de projetos}

O Valor Presente Líquido, também conhecido como Valor Atual Líquido [VAL], consiste em trazer para o instante atual, todos os fluxos de caixa projetados, descontando-os a uma Taxa Mínima de Atratividade TMA, em seguida somá-los algebricamente. Se o VPL for positivo o investimento é viável economicamente, se for negativo é inviável, e se for igual 0 se torna indiferente aplicar os recursos no projeto ou na alternativa representada pela TMA (Nascimento, 2010; Reis e Aragão, 2015). A obtenção do VPL foi realizada pela eq. (1).

$$
\mathrm{VPL}=-\mathrm{I}+\sum_{\mathrm{t}=1}^{\mathrm{n}} \quad \frac{\mathrm{FC}_{\mathrm{t}}}{(1+\mathrm{k})^{\mathrm{t}}}
$$

onde, I: investimento inicial; t: período, sendo utilizado um período anual; $\mathrm{n}$ : tempo total do projeto (20 anos); $\mathrm{k}$ : Taxa Mínima de Atratividade [TMA], sendo considerado 6\% ao ano; FC: Fluxo de caixa por período.

O Valor Uniforme Líquido [VUL], segundo Lapponi (2007), consiste em transformar o VPL numa série uniforme de pagamentos postecipados, equivalente ao fluxo de caixa do projeto. Representa o fluxo de caixa líquido do projeto na forma anualizada. A obtenção do VUL foi realizada pela eq (2).

$$
\mathrm{VUL}=\mathrm{VPL} \frac{1-(1+\mathrm{i})^{-\mathrm{n}}}{\mathrm{i}}
$$

onde, VPL: valor presente líquido; i: taxa de desconto ou taxa mínima de atratividade; n: número de períodos.

A TIR é a taxa que iguala o valor presente das entradas ao valor presente das saídas de um projeto, ou seja, a taxa que anula o VPL. É a taxa pela qual o capital está sendo remunerado e deve ser comparada à TMA, caso seja maior que a mesma o projeto deve ser aceito, caso seja menor do que a TMA o projeto deve ser rejeitado $\mathrm{e}$ os recursos aplicados na alternativa representada pela referida taxa (Nascimento, 2010; Reis e Aragão, 2015). A TIR foi obtida por meio da eq (3). 


$$
0=-\mathrm{I}+\sum_{\mathrm{t}=1}^{\mathrm{n}} \quad \frac{\mathrm{FC}_{\mathrm{t}}}{(1+\mathrm{TIR})^{\mathrm{t}}}
$$

onde, I: investimento inicial; t: período, sendo utilizado período anual; n: tempo total do projeto (20 anos); TIR: taxa interna de retorno; FC: fluxo de caixa por período.

Índice de Lucratividade [IL] mede o retorno adicional (além da taxa mínima de atratividade) de cada unidade de capital investido. Consiste em trazer os fluxos de caixa futuros a valor presente e dividir pelo investimento inicial desconsiderando o sinal negativo. Deve ser aceito quando o índice for maior que 1 (Lapponi, 2007). O IL foi obtido pela eq. (4).

$$
\mathrm{IL}=\frac{\text { P. Retornos }}{\mathrm{I}}
$$

onde, P. Retornos: Valor presente dos retornos futuros do fluxo de caixa; I: Investimento Inicial.

Payback simples é o cálculo do tempo necessário para que o lucro líquido acumulado se iguale ao valor do investimento. Basicamente, é período de tempo que o investidor leva para recuperar o capital investido, geralmente expresso em anos. O Payback descontado é calculado da mesma forma que o Payback simples, porém acumulando os fluxos descontados à taxa mínima de atratividade, ou seja, levando em consideração o valor do dinheiro no tempo. Consiste em montar um novo fluxo de caixa, trazendo os fluxos líquidos futuros a valor presente, descontados pela TMA, e acumulá-los algebricamente, ano a ano, identificando o momento no qual se torna positivo. Após isso aplicar a fórmula descrita na eq. (5) (Lapponi, 2007).

$$
\mathrm{PBD}=\frac{\mathrm{UFAN}}{\mathrm{UFAN}+\mathrm{PFAP}} \cdot(\mathrm{PAP}-\mathrm{UAN})+\mathrm{UAN}
$$

onde, PBD: Payback descontado; UFAN: valor do último fluxo acumulado negativo; PFAP: valor do primeiro fluxo acumulado positivo; PAP: primeiro ano positivo, expresso em quantidade de anos; UAN: último ano negativo, expresso em quantidade de anos.

\section{Análise de sensibilidade}

Reconhecendo a impossibilidade de prever com exatidão os fluxos de caixa futuros e, em consequência, a existência do risco de que os projetos após serem colocados em operação, não resultem em VPL positivo com geração de valor para o investidor, foi efetuada análise pela Simulação de Monte Carlo conforme Lapponi (2007).

Tal método consiste em identificar as variáveis mais importantes do projeto, definir suas distribuições de probabilidade e gerar, com a ajuda de softwares, várias estimativas aleatórias de cada variável escolhida. Resultando em várias séries de fluxo de caixa com seus respectivos VPL e demais indicadores. Por fim, aplicar métodos estatísticos como média e desvio padrão para medir os riscos do projeto. Dessa maneira é possível capturar os riscos de variação do fluxo de caixa ao longo período e medir a sensibilidade dos projetos.

Nos empreendimentos analisados, as variáveis aleatórias utilizadas no método de Monte Carlo foram: preços, custos variáveis e produtividade. A partir das mesmas, foram geradas 3.000 (três mil) simulações de fluxo de caixa e resultados para o VPL.

Nos preços foi considerada uma distribuição normal, com média e desvio padrão apurados com base nas séries Cepea (2016) para a laranja e Agrolink (2016) para os grãos, conforme explicado anteriormente, capturando as variações de preço dos últimos cinco anos.

Para os custos variáveis, conforme pesquisa com os produtores, foi considerada uma distribuição discreta contendo três cenários: "esperado" (projetado) com 80\% de probabilidade de ocorrência, "otimista" (queda de $10 \%$ no custo projetado) com $5 \%$ de probabilidade de ocorrência e "pessimista" (aumento de 20\% sobre o projetado) com $15 \%$ de probabilidade de ocorrência. As bases para os cenários "esperados" são os custos variáveis projetados na pesquisa e detalhados mais adiante, nas seções de receitas, custos e lucro operacional de cada empreendimento. E, a partir dos cenários esperados, aplicou-se os percentuais de aumento ou queda para obter os valores dos cenários "pessimista" e "otimista".

Para produtividade, também conforme pesquisa com os produtores, foram simulados os mesmos cenários e probabilidades dos custos variáveis, porém com os cenários "otimista" representando aumento de 5\% e "pessimista" representando perda de $20 \%$. Assim como nos custos variáveis, as bases para os cenários "esperados" são as produtividades projetadas na pesquisa e detalhadas mais adiante nas mesmas seções já citadas.

Com os resultados das simulações elaboradas no Excel, foi possível calcular as médias e desvios padrão dos VPLs de ambos os projetos. Foi calculado ainda, a probabilidade de os VPLs resultarem em valores negativos, propiciando medida do risco dos projetos.

Com os vários indicadores obtidos, foi possível comparar os dois empreendimentos e concluir sobre qual é o mais viável economicamente ao produtor rural e/ou investidor.

\section{Resultados e Discussão}

\section{Pomar de laranja - Investimento Inicial}

Como característica peculiar da cultura de citrus, e também de outras lavouras perenes, o empreendimento exige um alto grau de investimento inicial, com déficits de caixa nos primeiros anos, até que o pomar atinja a plena produção e, por consequência, o fluxo positivo do projeto. Esse investimento é detalhado a seguir, na Tabela 1. 
Tabela 1. Investimento inicial em pomar de laranja de 100 hectares arrendados na região de Paranapanema, SP

\begin{tabular}{lrr}
\hline \multicolumn{1}{c}{ Descrição } & Quantidade & Valor total \\
\hline & & 2 \\
Trator com cabine 85 cavalos & 1 & $220.000,00$ \\
Trator sem cabine 85 cavalos & 2 & $85.000,00$ \\
Atomizadores 4000 litros & 1 & $90.000,00$ \\
Roçadeira 2,6 metros & 1 & $25.000,00$ \\
Adubadeira & 1 & $25.000,00$ \\
Guincho Hidráulico & 1 & $12.000,00$ \\
Barra de herbicida & 1 & $8.000,00$ \\
Outros investimentos & 1 & $50.000,00$ \\
Correção de solo e plantio (ano 0) & 1 & $636.008,00$ \\
Custos fixos desembolsáveis do ano 0 & 1 & $252.380,00$ \\
Provisão para custos variáveis do ano 1 & 1 & $278.802,01$ \\
Provisão para custos fixos desembolsáveis ano 1 & 1 & $243.663,08$ \\
Provisão para custos variáveis do ano 2 & 1 & $241.995,76$ \\
Provisão para custos fixos desembolsáveis ano 2 & 1 & $235.247,24$ \\
Provisão para déficit de caixa ano 3 & 1 & $241.040,41$ \\
Provisão troca parque de máquinas no ano 10 & 1 & $362.372,51$ \\
Provisão para Capital de giro a partir do ano 4 & & $403.467,79$ \\
\hline Total & & $3.409 .976,80$ \\
\hline
\end{tabular}

O investimento em correção de solo e plantio foi orçado em $\mathrm{R} \$ 6.360,08$ por hectare, contendo despesas com insumos, mão de obra, operações com máquinas mudas e proteção fitossanitária. Seguido pelos custos variáveis de manutenção do pomar no ano 1 e 2 , orçados em $\mathrm{R} \$ 2.887,76$ e $\mathrm{R} \$ 2.596,20$, respectivamente, e contendo a mesma estrutura, com exceção das mudas.

Os custos fixos desembolsáveis, orçados em R\$ 252.380,00 durante a vida útil do projeto, representa as despesas com funcionários fixos de campo e de escritório (com encargos), seguros de máquinas, despesas fixas de administração, arrendamento de $\mathrm{R} \$ 910,00$ por hectare/ano e outros.

Conforme já descrito anteriormente, a produção é crescente a partir do terceiro ano. Porém, especificamente no seu início, espera-se uma produção pequena e insuficiente para honrar todos os compromissos, gerando necessidade de recursos adicionais para cobrir o fluxo negativo do mesmo, sendo assim foram provisionados no investimento inicial, o valor de $\mathrm{R} \$ 541.040,41$ para tal fim.

A vida útil estimada para o parque de máquinas foi de 10 anos, com valor residual de 5\%. Gerando a necessidade de uma renovação durante a execução do projeto, orçada em $\mathrm{R} \$ 515.000,00$, e que também foi provisionada no investimento inicial, assim como o capital de giro necessário a partir do quarto ano, orçado em $\mathrm{R} \$ 464.375,89$.

Como citado anteriormente, todas as provisões foram trazidas a valor presente pelo custo de oportunidade de aplicação em Letra de crédito do Agronegócio, para serem resgatadas de acordo com o cronograma e representam 58,84\% do investimento inicial.

\section{Receitas, Custos e Lucro operacional do projeto (a partir do terceiro ano)}

De acordo com a pesquisa, após os investimentos iniciais no plantio e na manutenção até ano 2, o pomar inicia a produção, crescendo do ano 3 ao 13 e seguindo em declínio do ano 14 ao 20. As produtividades, em caixas por hectare, estão detalhadas na Tabela 2, juntamente com outros dados que resultam no lucro operacional do projeto.

A partir do preço médio de $\mathrm{R} \$ 12,51$ por caixa de $40,8 \mathrm{Kg}$ da fruta, calculado com base na série CEPEA (2016), e da produtividade por hectare, chegamos à receita bruta, que é tributada a 2,3\% (Funrural e demais encargos) e gera a receita líquida do projeto também detalhada na Tabela 2.

Em se tratando de custos, foram computados os mesmos desembolsos considerados por Simões et al. (2015), intrínsecos à qualquer empreendimento de laranja, como despesas administrativas, salários (com encargos), herbicidas, manutenção de máquinas, combustível, etc. e que refletem o custeio da atividade. Porém foram organizados em uma estrutura diferente, separados em (a) custos variáveis, compostos por insumos, mão de obra e operações com máquinas e (b) custos fixos desembolsáveis; não considerando custo de remuneração do capital, uma vez que o mesmo será capturado pelo modelo matemático do VPL. Nota-se ainda que os custos projetados nas duas pesquisas divergem consideravelmente devido a dados como região produtora, número de plantas por hectare, espaçamento, etc. 
Tabela 2. Receitas, Custos e Lucro operacional a partir do terceiro ano, para o plano de cultivo de pomar de laranjeiras na região de Paranapanema, SP

\begin{tabular}{|c|c|c|c|c|c|}
\hline Ano & Produtividade & $\begin{array}{c}\text { Receita líquida } \\
\text { total }\end{array}$ & $\begin{array}{c}\text { Custos } \\
\text { Variáveis } \\
\end{array}$ & $\begin{array}{c}\text { Custos } \\
\text { Fixos desembolsáveis } \\
\end{array}$ & $\begin{array}{c}\text { Lucro Operacional } \\
\text { Bruto } \\
\end{array}$ \\
\hline & ------caixas ha'-1------ & & & $\mathrm{PS}$ & ----------------------------- \\
\hline 3 & 416 & $509.282,79$ & $524.748,97$ & $252.380,00$ & $(267.846,18)$ \\
\hline 4 & 1.166 & $1.425 .991,96$ & $791.500,97$ & $252.380,00$ & $382.110,99$ \\
\hline 5 & 1.833 & $2.240 .844,60$ & $1.153 .636,99$ & $252.380,00$ & $834.827,61$ \\
\hline 6 & 1.833 & $2.240 .844,60$ & $1.159 .291,99$ & $252.380,00$ & $829.172,61$ \\
\hline 7 & 1.833 & $2.240 .844,60$ & $1.130 .921,99$ & $252.380,00$ & $857.542,61$ \\
\hline 8 & 1.833 & $2.240 .844,60$ & $1.141 .408,99$ & $252.380,00$ & $847.055,61$ \\
\hline 9 & 1.833 & $2.240 .844,60$ & 1.121.698,99 & $252.380,00$ & $866.765,61$ \\
\hline 10 & 1.833 & $2.240 .844,60$ & $1.137 .578,99$ & $252.380,00$ & $850.885,61$ \\
\hline 11 & 2.250 & $2.750 .127,51$ & 1.307.688,00 & $252.380,00$ & $1.190 .059,51$ \\
\hline 12 & 2.250 & $2.750 .127,51$ & $1.351 .379,00$ & $252.380,00$ & $1.146 .368,51$ \\
\hline 13 & 2.250 & $2.750 .127,51$ & $1.307 .688,00$ & $252.380,00$ & $1.190 .059,51$ \\
\hline 14 & 1.833 & $2.240 .844,60$ & $1.137 .578,99$ & $252.380,00$ & $850.885,61$ \\
\hline 15 & 1.833 & $2.240 .844,60$ & $1.129 .658,99$ & $252.380,00$ & $858.805,61$ \\
\hline 16 & 1.833 & $2.240 .844,60$ & $1.163 .878,99$ & $252.380,00$ & $824.585,61$ \\
\hline 17 & 1.500 & $1.833 .418,34$ & $982.683,00$ & $252.380,00$ & $598.355,34$ \\
\hline 18 & 1.500 & $1.833 .418,34$ & $966.936,00$ & $252.380,00$ & $614.102,34$ \\
\hline 19 & 1.500 & $1.833 .418,34$ & $971.511,00$ & $252.380,00$ & $609.527,34$ \\
\hline 20 & 1.500 & $1.833 .418,34$ & $993.236,00$ & $252.380,00$ & $587.802,34$ \\
\hline
\end{tabular}

Ainda no campo de custos, destacam-se as despesas com mão de obra na colheita e o frete, orçados em $\mathrm{R} \$$ 2,20 e $\mathrm{R} \$ 2,30$ por caixa, respectivamente, chegando a representar $77 \%$ do custo variável total no ano 11 . De acordo com Simões et al. (2015), o produtor que não possui contratos específicos com a indústria de transformação, assume os custos com colheita e frete, o que se aplica a esta pesquisa.

As variáveis identificadas como de maior risco foram preços de venda da fruta, produtividade do pomar e custos. E, apesar de os preços da fruta e dos insumos sofrerem influência do câmbio e do preço externo do suco de laranja concentrado congelado ${ }^{2}$, não há fórmula contábil no fluxo de caixa relacionando o impacto dessas variáveis, esperando capturar o risco através das variações nas distribuições de probabilidade pelo método de Monte Carlo.

\section{Fluxo de caixa e avaliação do projeto}

A partir dos dados de investimento e fluxo operacional, foi construído o Fluxo de Caixa, apresentado resumidamente na tabela 3 .

O projeto apresentou um VPL de R $\$ 2.625 .495,12$, ou seja, remunera o capital a taxa mínima de atratividade de $6 \%$ ao ano e ainda gera expressivo lucro econômico para o investidor; o que, conforme Nascimento (2010), indica que o projeto deve ser aceito. $O$ Índice de lucratividade foi de 1,77 (maior que 1) e o VUL calculado foi de $\mathrm{R} \$ 228.902,63$ (maior que 0), reforçando a indicação aceitação do projeto.

A TIR calculada foi de $12,09 \%$, maior do que o valor de 7,7\% da Taxa Interna de Retorno Modificada [MTIR] apurada em Simões et al. (2015), por conta justamente do método de cálculo, mas também por variáveis como regiões produtoras diferentes e espaçamento entre plantas que refletem na produtividade e no fluxo de caixa. Segundo Lapponi (2007), quando a TIR é maior que a TMA considerada no projeto, há a indicação de aceitação do mesmo, situação que se aplica a este estudo, uma vez que a TMA considerada foi $6 \%$.

Pelo método de payback descontado, foi identificado que o investidor leva 11,06 anos para recuperar o capital investido remunerado pela taxa requerida, prazo que deve ser ponderado quando da decisão de entrar no negócio, principalmente pela dificuldade de substituição da cultura perene por outras opções de investimento na área rural.

Pelo método de Monte Carlo foram simuladas as variações de preço, produtividade e custos variáveis, resultando em um VPL médio de R \$2.007.539,03, com 2,87\% de probabilidade de obtenção de VPL negativo; resultado de difícil comparação ao apurado por Simões et al. (2015), pois naquela pesquisa foi avaliado empreendimento de laranja em outra região, com outros dados de espaçamento entre plantas, além de outras variáveis diferentes.

Ainda analisando os resultados das simulações, observou-se que o desvio padrão foi de R \$ 1.056.755,69. Com resultados variando entre o VPL mínimo (negativo) de $\mathrm{R} \$ 1.833 .872,64$ e máximo (positivo) de $\mathrm{R} \$$ $5.821 .972,29$, intervalo que pode ser considerado alto e significar risco para o produtor. Entretanto, os valores negativos ocorreram em baixa frequência, conforme demonstrado no histograma exibido a seguir, na Figura 1.

${ }^{2}$ Idem nota 1 
Tabela 3. Fluxo de caixa resumido para o plano de cultivo de pomar de laranjeiras na região de Paranapanema, SP

\begin{tabular}{|c|c|c|c|c|c|}
\hline Ano & $\begin{array}{c}\text { Lucro } \\
\text { Operacional }(+)\end{array}$ & $\begin{array}{l}\text { Fluxo do investimento } \\
(-)\end{array}$ & $\begin{array}{c}\text { Provisão/Recup. } \\
\text { Capital/Valor residual* } \\
(+)\end{array}$ & Imposto Renda(-) & $\begin{array}{c}\text { Fluxo de } \\
\text { caixa líquido } \\
(=)\end{array}$ \\
\hline & & & $K \$$ & 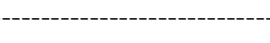 & -------------------- \\
\hline 0 & & $3.409 .976,80$ & & & $(3.409 .976,80)$ \\
\hline 1 & & $541.156,00 * *$ & $541.156,00$ & & 0,00 \\
\hline 2 & & $512.000,00 * *$ & $512.000,00$ & & 0,00 \\
\hline 3 & $(267.846,18)$ & & $267.846,18$ & & 0,00 \\
\hline 4 & $382.110,99$ & & & & $382.110,99$ \\
\hline 5 & $834.827,61$ & & & & $834.827,61$ \\
\hline 6 & $829.172,61$ & & & & $829.172,61$ \\
\hline 7 & $857.542,61$ & & & $38.865,19$ & $818.677,43$ \\
\hline 8 & $847.055,61$ & & & $222.507,97$ & $624.547,64$ \\
\hline 9 & $866.765,61$ & & & $227.928,22$ & $638.837,39$ \\
\hline 10 & $850.885,61$ & $515.000,00^{* * *}$ & $25.750,00$ & $89.017,47$ & $272.618,14$ \\
\hline 11 & $1.190 .059,51$ & & & $316.834,05$ & $873.225,47$ \\
\hline 12 & $1.146 .368,51$ & & & $304.819,02$ & $841.549,49$ \\
\hline 13 & $1.190 .059,51$ & & & $316.834,05$ & $873.225,47$ \\
\hline 14 & $850.885,61$ & & & $223.561,22$ & $627.324,39$ \\
\hline 15 & $858.805,61$ & & & $225.739,22$ & $633.066,39$ \\
\hline 16 & $824.585,61$ & & & $216.328,72$ & $608.256,89$ \\
\hline 17 & $598.355,34$ & & & $154.115,40$ & $444.239,94$ \\
\hline 18 & $614.102,34$ & & & $158.445,82$ & $455.656,62$ \\
\hline 19 & $609.527,34$ & & & $157.187,70$ & $452.339,64$ \\
\hline 20 & $587.802,34$ & & $1.222 .038,47$ & $158.294,57$ & $1.651 .546,24$ \\
\hline
\end{tabular}

* Refere-se ao resgate dos valores provisionados para pagamento de investimentos dos anos 1 ao 3, a recuperação de capital de giro no ano 20 e ao valor residual da venda de equipamentos no ano 10 e 20.

** Refere-se ao pagamento de investimentos por meio do resgate das provisões.

*** Investimento efetuado com recursos do fluxo operacional do ano 10, a recuperação do valor provisionado para esse fim se dará ano 20 .

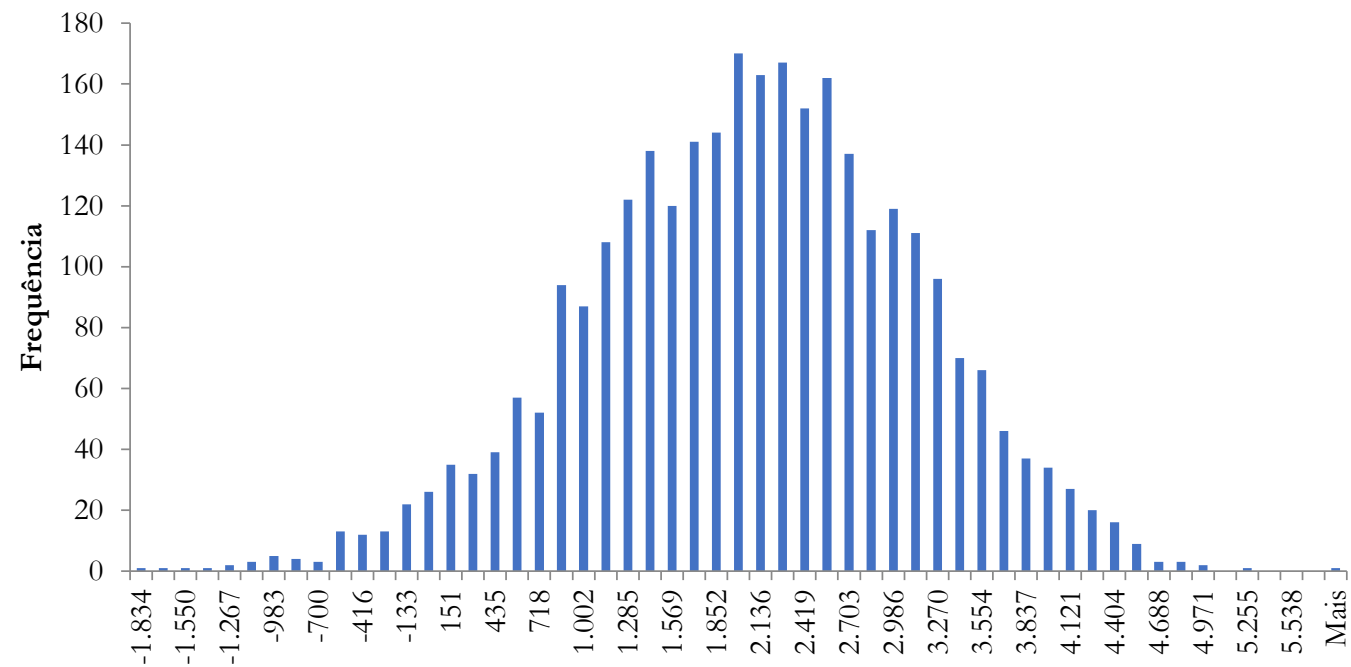

Intervalos de distribuição de VPL (em milhares de R\$)

Figura 1. Histograma da distribuição de resultados para o Valor Presente Líquido [VPL] no projeto de plantio do pomar de laranja

Apesar da baixa probabilidade do projeto obter $\mathrm{VPL}<0$, existe risco do mesmo apresentar fluxo negativo em algum período durante a sua execução, exigindo complemento de caixa que deverá ser suprido com recursos próprios ou mediante captação de crédito rural 
no mercado financeiro, em ambos os casos impactando o resultado final.

\section{Riscos associados à cultura}

Importante destacar dois dos principais riscos da citricultura, sendo (a) mercado comprador concentrado e (b) ameaça aos pomares devido a incidência de Greening, ou Huanglongbing [HLB], e que não foram considerados na avaliação econômica do projeto, e que serão detalhados posteriormente.

A fruta colhida nas propriedades é vendida, principalmente, para indústrias exportadoras de suco. Como resultado, existe um mercado comprador bastante concentrado e com grandes riscos de prejuízos ao produtor, como por exemplo, formação de cartel. Tais riscos são ainda maiores quando se comercializa a fruta no mercado spot, ou seja, sem contrato, situação na qual o presente trabalho foi desenvolvido. Porto (2016) relata que, em novembro de 2016, as seis empresas que compunham a extinta associação do setor [Abecitrus] e nove pessoas físicas assinaram um Termo de Compromisso de Cessação [TCC], no valor de R\$ 301 milhões, com o Conselho Administrativo de Defesa Econômica [CADE], no qual admitiram a formação de cartel nas negociações para a compra da fruta e se comprometeram a cessar a prática.

Com relação a pragas e doenças, a que mais preocupa os produtores é o "Greening” (Huanglongbing/HLB), considerada a mais destrutiva doença de Citrus no Brasil. Essa doença tem como agentes causais Candidatus Liberibacter asiaticus e Candidatus Liberibacter americanus, a doença causa grandes prejuízos financeiros, variando desde a perda de produtividade das plantas até a erradicação de todo o pomar, e, por consequência, impossibilidade de recuperação do capital investido. (Fundecitrus, 2016a).

A Instrução normativa $\mathrm{n}^{\circ} 53$ do Ministério da Agricultura, exige que os produtores inspecionem e eliminem, periodicamente, as plantas doentes, pois não há cura e nem variedades comerciais de copa ou portaenxerto que sejam resistentes à doença (Fundecitrus, 2016a).

De acordo com Fundecitrus (2016b, c), a região de Avaré (na qual incluem-se Paranapanema e demais municípios da região estudada) acompanhou seu índice de árvores sintomáticas evoluir de 5,7\% em 2015 para $8,2 \%$ em 2016. Entretanto, a região pode ser considerada de baixa incidência, se comparada aos 48,3\% em 2016, registrado na região de Brotas, SP. Dentre os mecanismos para prevenção e controle, existe um grupo regional formado com o intuito de realizar pulverizações em conjunto e fazer reuniões para alinhar as técnicas de manejo do HLB, buscando minimizar os impactos da doença.

\section{Plantio irrigado de grãos - Investimento inicial}

Para o cultivo de grãos, a pesquisa apurou um investimento inicial de $\mathrm{R} \$ 2.464 .411,99$, detalhado na Tabela 4. Esse valor representa $72,27 \%$ do valor do investimento no pomar de laranja, o que pode ser considerado uma relação alta, uma vez que, pela condição de perenidade do pomar de laranja, se espera que essa relação seja mais baixa. No entanto, esse orçamento é impactado pelo investimento em aquisição e montagem do sistema de irrigação por pivô central, importante para o atingimento de altos níveis de produtividade e mitigação de alguns riscos de intempéries.

Tabela 4. Investimento Inicial no cultivo irrigado de grãos em 100 hectares arrendados na região de Paranapanema, SP

\begin{tabular}{|c|c|c|}
\hline Descrição & Quantidade & Valor Total \\
\hline & & 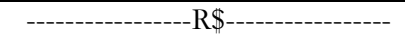 \\
\hline Trator de $110 \mathrm{cv}$ com cabine & 1 & $173.000,00$ \\
\hline Trator de $75 \mathrm{cv}$ sem cabine & 1 & $89.000,00$ \\
\hline Plantadeira de 9 linhas & 1 & $137.800,00$ \\
\hline Pulverizador $2000 \mathrm{~L}$ barra $18 \mathrm{~m}$ & 1 & $54.800,00$ \\
\hline Guincho $2 \mathrm{t}$ & 1 & $13.500,00$ \\
\hline Distribuidor de adubo à lanço $1300 \mathrm{~kg}$ & 1 & $13.040,00$ \\
\hline Distribuidor de calcário $5 \mathrm{t}$ & 1 & $26.860,00$ \\
\hline Carreta de 4 rodas, capacidade $10 t$ & 1 & $16.120,00$ \\
\hline Correção de solo em 100 ha & 1 & $50.000,00$ \\
\hline Pivô Central para irrigação 100 ha & 1 & $750.000,00$ \\
\hline Instalação de rede elétrica para pivô central & 1 & $50.000,00$ \\
\hline Outros investimentos & 1 & $50.000,00$ \\
\hline Provisão para troca de máquinas ano 10 & 1 & $403.971,47$ \\
\hline Capital de giro & 1 & $636.320,52$ \\
\hline Total & & $2.464 .411,99$ \\
\hline
\end{tabular}

Assim como no investimento de laranja, há necessidade de se dispor recursos para o capital de giro das atividades, orçado em R\$ 636.320,52 e computado no investimento inicial.
O parque de máquinas foi dividido em dois grupos, sendo: (a) tratores e implementos, com vida útil estimada de 10 anos e valor residual de $5 \%$, orçados em $\mathrm{R} \$$ $574.120,00$ e provisionados no investimento inicial, 
conforme método já descrito; e (b) pivô central para irrigação, com vida útil estimada de 20 anos e valor residual de $10 \%$, não sendo necessário renovação durante a execução do projeto.

Não foi orçada aquisição de colhedoras de grãos uma vez que, pelo tamanho da área, é mais vantajoso contratar serviços terceirizados de colheita, já orçados nos custos variáveis das lavouras.

\section{Receitas, Custos e Lucro operacional do projeto}

A partir das séries de preço obtidas pelo site Agrolink (2016) foi possível chegar aos preços médios (por saca) de $R$ \$ 166,30 para o feijão, $R$ \$ 71,51 para a soja, $R$ \$ 32,36 para o milho safrinha e $\mathrm{R} \$ 45,07$ para o trigo. Há de se ponderar o efeito que a variação do dólar americano pode causar nos preços desses produtos, principalmente em um projeto de longo prazo. Porém, através das médias e desvios padrão calculadas, buscou-se capturar o risco de variação através da simulação de Monte Carlo e os impactos que o mesmo pode causar no fluxo de caixa.

A produtividade média apurada na pesquisa, em sacas por hectare, foi de 50 para o feijão, 67 para a soja, 140 para o milho safrinha e 66 para o trigo, considerando um risco de queda de $20 \%$ na produtividade com $15 \%$ de probabilidade para a simulação de Monte Carlo. Ao multiplicar essas produtividades pelos preços médios acima, obteve-se a receita bruta que, tributada a 2,3\% (Funrural e demais encargos), resultou na receita líquida do empreendimento.

Os preços da soja e milho safrinha considerados em Sousa et al. (2013), após deflacionados pelo índice IGPDI conforme método já descrito, são semelhantes aos observados nesta pesquisa. Já as produtividades das duas culturas não se aproximam tanto, uma vez que Sousa et al. (2013), pesquisando a viabilidade da sucessão sojamilho safrinha em Ipameri e Campo Alegre de Goiás, no sudeste goiano, chegou a 55 sacas por hectare para soja e 110 para milho safrinha. Porém, deve-se levar em conta fatores como clima das regiões pesquisadas, sistemas de produção e irrigação que podem influenciar positivamente o rendimento das lavouras na região de Paranapanema - SP.

Custos fixos desembolsáveis, incluindo despesas com funcionários fixos de campo e escritório (com encargos), despesas de administração, arrendamento de $\mathrm{R} \$ 910,00$ por hectare/ano e seguros totalizaram R\$ 219.689,44.

Os custos variáveis estimados em reais por hectare foram $\mathrm{R} \$ 3.665,41$ para o feijão, $\mathrm{R} \$ 2.746,78$ para a soja, $\mathrm{R} \$ 2.644,26$ para o milho safrinha e $\mathrm{R} \$ 2.144,73$ para o trigo. Esses também expostos a variação cambial, uma vez que a maior parte dos insumos aplicados nas lavouras são importados.

O lucro operacional apurado de acordo com os dados acima resultou em um valor de $\mathrm{R} \$ 321.757,46$, constante durante a vida útil do projeto.

\section{Fluxo de caixa e avaliação do projeto}

A partir dos dados de investimento inicial e fluxo operacional, foi construído o fluxo de caixa do projeto apresentado na Tabela 5.

O projeto apresentou avaliação econômica satisfatória em todos os indicadores sendo VPL de R\$ 902.977,92, VUL de R $\$ 78.725,73$, índice de lucratividade de 1,37 e TIR de 9,93\%, o que indica a aceitação do mesmo.

Em comparação, o cultivo de grãos em área arrendada, no município de Paranapanema - SP, apresentou TIR menor do que os $24,26 \%$ observados no sistema de sucessão soja-milho safrinha, com arrendamento na região sudeste Goiana, pesquisado por Sousa et al. (2013). No entanto, o VPL por hectare obtido em Paranapanema - SP, foi superior aos R\$ 7.999,38 apurados naquela região.

O Payback descontado de 14,04 anos merece especial atenção quando da análise pelo investidor. Pois como se trata do plantio de culturas temporárias, em geral, esperase um menor prazo de retorno do capital; como, por exemplo, os 5,18 anos observados em Sousa et al. (2013). Sendo assim, o maior tempo de retorno do capital foi impactado pelo alto grau de investimento em máquinas e sistema de irrigação das lavouras, resultando em um Payback deslocado da expectativa de mercado, porém trazendo outros benefícios como maior produtividade esperada e mitigação de alguns riscos climáticos.

Na Simulação de Monte Carlo, o VPL médio foi de $\mathrm{R} \$ 457.685,23$, com 7,05\% de chance de apresentar VPL negativo. Assim como no pomar de laranja, a probabilidade de VPL $<0$ obtida pode ser considerada baixa, porém há o risco de se obter fluxos intermediários negativos. Nesse risco destaca-se o preço da saca de feijão que possui preço médio de $\mathrm{R} \$ 166,30$, com um desvio padrão alto $(\mathrm{R} \$ 53,69)$ gerando grande potencial de impacto nesses fluxos.

As grandes variações no preço do feijão são objeto de estudo na maioria dos projetos que envolvem a cultura. Na pesquisa realizada por Silva et al. (2011) foi estudado a viabilidade do cultivo em Minas Gerais, considerando o preço da saca na Simulação de Monte Carlo. Chegou-se a um VPL médio de R \$234.054,40 com desvio padrão de $\mathrm{R} \$ 406.069,40$, reforçando a influência da variável no resultado do projeto.

Como feito na avaliação da laranja, ao detalhar as simulações de resultados para o VPL, foi encontrado um desvio padrão de $\mathrm{R} \$ 310.871,70$. Com resultados variando entre o VPL mínimo (negativo) de $\mathrm{R} \$$ 811.196,20 e máximo (positivo) de $\mathrm{R} \$ 1.548 .945,54$, intervalo que também pode ser considerado alto e pôr em risco o capital do investidor. Todavia, semelhante ao ocorrido no projeto de laranja, os valores negativos ocorreram em baixa frequência, conforme demonstrado no histograma exibido a seguir, na Figura 2 
Tabela 5. Fluxo de caixa resumido para o plano de cultivo de grãos na região de Paranapanema, SP

\begin{tabular}{|c|c|c|c|c|c|}
\hline Ano & $\begin{array}{c}\text { Lucro } \\
\text { Operacional (+) }\end{array}$ & $\begin{array}{c}\text { Fluxo do } \\
\text { investimento (-) }\end{array}$ & $\begin{array}{c}\text { Provisão/Recup. } \\
\text { Capital/Valor residual* (+) }\end{array}$ & Imposto Renda(-) & $\begin{array}{l}\text { Fluxo de caixa } \\
\text { líquido }(=)\end{array}$ \\
\hline & -------R\$-------- & --------R\$-------- & 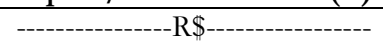 & -----R\$------ & 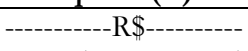 \\
\hline $\mathbf{0}$ & & 2.464.411,98 & & & $(2.464 .411,98)$ \\
\hline 1 & $321.757,46$ & & & & $321.757,46$ \\
\hline 2 & $321.757,46$ & & & & $321.757,46$ \\
\hline 3 & $321.757,46$ & & & & $321.757,46$ \\
\hline 4 & $321.757,46$ & & & & $321.757,46$ \\
\hline 5 & $321.757,46$ & & & $40.351,19$ & $281.406,27$ \\
\hline 6 & $321.757,46$ & & & $78.050,98$ & $243.706,48$ \\
\hline 7 & $321.757,46$ & & & $78.050,98$ & $243.706,48$ \\
\hline 8 & $321.757,46$ & & & $78.050,98$ & $243.706,48$ \\
\hline 9 & $321.757,46$ & & & $78.050,98$ & $243.706,48$ \\
\hline 10 & $321.757,46$ & $574.120,00^{* *}$ & $252.362,54$ & & 0,00 \\
\hline 11 & $321.757,46$ & & & $16.545,43$ & $305.212,03$ \\
\hline 12 & $321.757,46$ & & & $78.050,98$ & $243.706,48$ \\
\hline 13 & $321.757,46$ & & & $78.050,98$ & $243.706,48$ \\
\hline 14 & $321.757,46$ & & & $78.050,98$ & $243.706,48$ \\
\hline 15 & $321.757,46$ & & & $78.050,98$ & $243.706,48$ \\
\hline 16 & $321.757,46$ & & & $78.050,98$ & $243.706,48$ \\
\hline 17 & $321.757,46$ & & & $78.050,98$ & $243.706,48$ \\
\hline 18 & $321.757,46$ & & & $78.050,98$ & $243.706,48$ \\
\hline 19 & $321.757,46$ & & & $78.050,98$ & $243.706,48$ \\
\hline 20 & $321.757,46$ & & & $78.050,98$ & $243.706,48$ \\
\hline
\end{tabular}

* Refere-se ao resgate dos valores provisionados para pagamento de investimentos do ano 10, a recuperação de capital de giro no ano 20 e ao valor residual da venda de equipamentos nos anos 10 e 20.

** Refere-se ao pagamento de investimentos por meio do resgate das provisões somado ao fluxo operacional do período

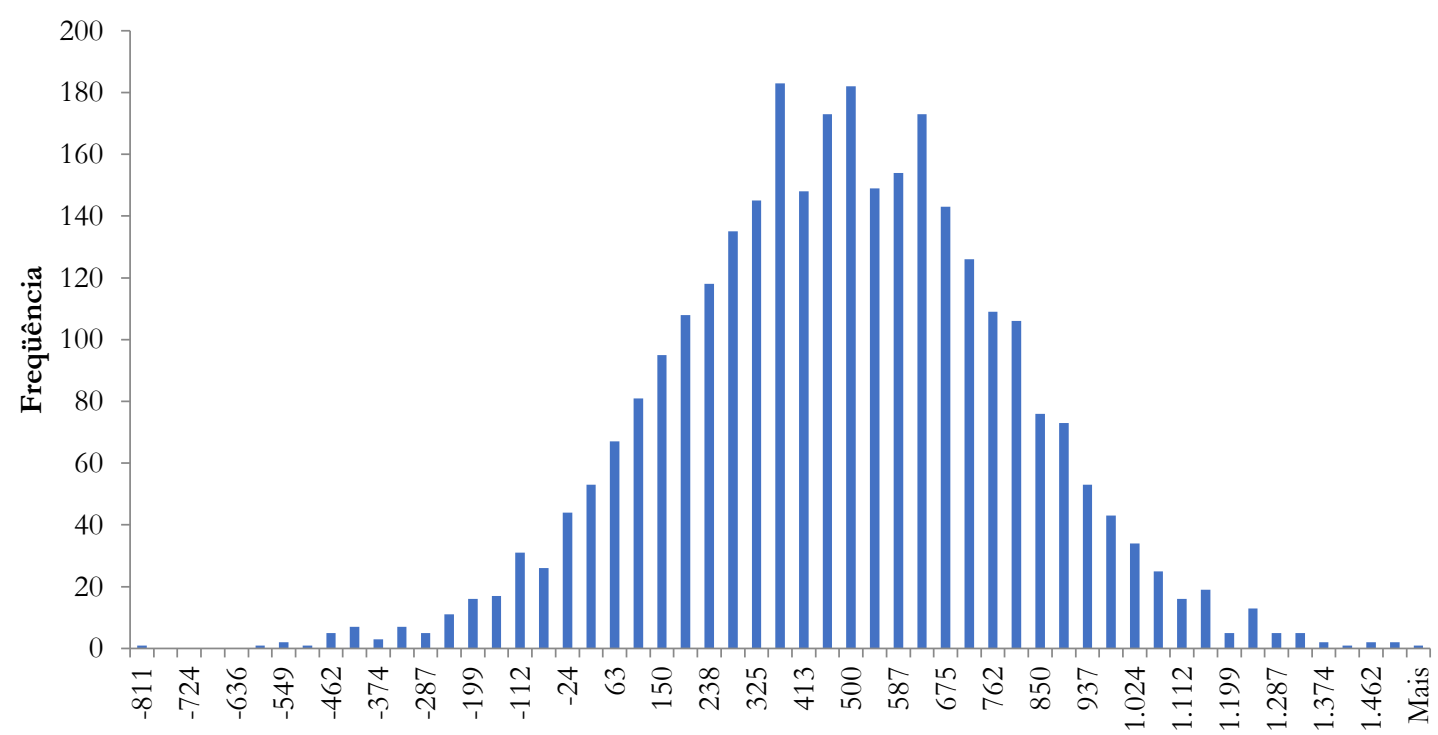

Intervalos de distribuiçao de VPL (em milhares de R\$)

Figura 2. Histograma da distribuição de resultados para o Valor Presente Líquido [VPL] no projeto de cultivo de grãos

\section{Comparação e seleção entre os projetos}

$\mathrm{Na}$ Tabela 6 segue a comparação dos diversos indicadores resultantes da pesquisa, para os dois empreendimentos.

Segundo Lapponi (2007), na seleção entre projetos excludentes, ou seja, quando a aceitação de um obriga a rejeição de outro, a avaliação pelo método VPL é a mais indicada. No entanto, quando se opta por avaliar vários indicadores, a TIR muitas vezes gera conflito nas decisões, uma vez que pode divergir da indicação do VPL e, nesse caso, deve-se utilizar a análise do fluxo de caixa incremental. Como a presente pesquisa não apresentou divergência, o referido método não foi realizado. 
Tabela 6. Comparação entre os resultados dos indicadores do pomar de laranja e cultivo de grãos na região de Paranapanema, SP

\begin{tabular}{lcrr}
\hline \multicolumn{1}{c}{ Indicadores } & Unidade & \multicolumn{1}{c}{ Laranja } & \multicolumn{1}{c}{ Grãos } \\
\hline VPL* & $\mathrm{R} \$$ & $2.625 .495,12$ & $902.977,92$ \\
TIR** & $\%$ & 12,09 & 9,93 \\
$\begin{array}{l}\text { VUL** } \\
\text { Índice de }\end{array}$ & $\mathrm{R} \$$ & $228.902,63$ & $78.725,73$ \\
$\begin{array}{l}\text { lucratividade } \\
\text { Payback } \\
\text { descontado }\end{array}$ & anos & 1,77 & 1,37 \\
$\begin{array}{l}\text { Risco de } \\
\text { VPL }<0\end{array}$ & $\%$ & 11,06 & 14,04 \\
\hline
\end{tabular}

*VPL: Valor Líquido Presente; **TIR: Taxa Interna de Retorno; ***VUL: Valor Initário Líquido

Comparando os diversos indicadores individuais de cada projeto, verifica-se que em todos eles o pomar de laranja supera os resultados obtidos pelo cultivo de grãos.

\section{Conclusões}

O pomar de laranja apresentou bons índices de avaliação de projetos e um alto valor econômico por hectare de pomar, se comparado a outras culturas. Entretanto, expõe o produtor a diversos riscos que devem ser ponderados antes da tomada de decisão, como por exemplo: (a) o risco de comercialização do seu produto em um mercado comprador extremamente concentrado em poucas agroindústrias; (b) várias pragas e doenças, com destaque para o Greening/HLB, que pode significar necessidade de erradicação do pomar, prejudicando o retorno do investimento inicialmente projetado; (c) necessidade de alto investimento inicial para suportar primeiros anos de déficit de caixa até início da produção; e (d) dificuldade de substituição da cultura plantada, buscando melhores oportunidades de mercado, como ocorre em lavouras temporárias.

Através da irrigação por pivô central, o cultivo de grãos apresenta como vantagens, a mitigação de riscos de intempéries climáticas, possibilidade de rotação de várias safras na mesma área, além da boa distribuição do fluxo de receitas, uma vez que se trabalha com várias culturas com períodos diferentes de colheita. Em contrapartida, se comparado a culturas de sequeiro, exige um alto grau de investimento no parque de máquinas, comprometendo o tempo de retorno do investimento, além da necessidade de manejo mais intensivo e custos mais altos.

Entretanto, como o objetivo do presente trabalho foi analisar, exclusivamente, os retornos econômicos dos dois projetos, verificou-se que, com os mesmos riscos a serem ponderados, ambos se apresentaram viáveis economicamente. Todavia, o projeto de investimento no pomar de laranja apresenta melhores indicadores de avaliação, com menor risco. Dessa forma conclui-se que o mesmo apresenta melhor retorno econômico para o investidor. Destaca-se ainda o VPL da laranja, que gera valor econômico consideravelmente maior do que os grãos.

\section{Referências}

Agrolink. 2016. Cotações ao produtor. Disponível em: $<$ http://www.agrolink.com.br/cotacoes/Default.asp x>. Acesso em: 19 set. 2016.

Banco Central do Brasil. 2016. Calculadora do Cidadão: Correção de valores. Disponível em:

<https://www3.bcb.gov.br/CALCIDADAO/public o/exibirFormCorrecaoValores.do?method=exibirFor mCorrecaoValores >. Acesso em: 19 set. 2016.

Centro de Estudos Avançados em Economia Aplicada [CEPEA]. 2016. Séries Mensais. Disponível em: $<$ http:/ / cepea.esalq.usp.br/citros $/$ ?page $=707>$. Acesso em: 19 set. 2016

Centro de Pesquisas Meteorológicas e Climáticas Aplicadas a Agricultura [CEPAGRI]. 2016. Clima dos municípios Paulistas. Disponível em:

$<$ http://www.cpa.unicamp.br/outrasinformacoes/clima_muni_405.html>. Acesso em 03 jul. 2016.

Centro Regional de Informação das Nações Unidas [UNRIC]. 2015. ONU projeta que população mundial chegue aos 8,5 mil milhões em 2030. Disponível em: $<$ http://www.unric.org/pt/actualidade/31919-onuprojeta-que-populacao-mundial-chegue-aos-85-milmilhoes-em-2030>. Acesso em: 06 jun. 2016.

Companhia nacional de abastecimento [CONAB]. 2016a. $8^{\circ}$ Levantamento - Safra 2015/2016, Grãos. Disponível em: <http://www.conab.gov.br/conteudos.php?a=1253 \&\&Pagina_objcmsconteudos=1\#A_objcmsconteudo s>. Acesso em: 05 jun. 2016.

Companhia nacional de abastecimento [CONAB]. 2016b. Séries históricas, Brasil - Por produtos, grãos. Disponível em: $<$ http://www.conab.gov.br/conteudos.php?a $=1252$ \&ordem = produto\&Pagina_objcmsconteudos=2\#A_ objcmsconteudos >. Acesso em: 05 jun. 2016.

Fundecitrus. 2016a. Greening / HLB. Disponível em: $<$ http://www.fundecitrus.com.br/doencas/greening/ 10>. Acesso em: 25 nov. 2016.

Fundecitrus. 2016b. Pesquisa e Desenvolvimento. Disponível em: <http://www.fundecitrus.com.br/levantamentos/gre ening/10>. Acesso em: 25 nov. 2016.

Fundecitrus. 2016c. Alerta Fitossanitário. Disponível em: <http://www.fundecitrus.com.br/alertafitossanitario/2-avare>. Acesso em: 25 nov. 2016.

Instituto Brasileiro de Geografia Estatística [IBGE]. 2016. Cidades@: São Paulo>Paranapanema. Disponível em: $<$ http://cidades.ibge.gov.br/xtras/perfil.php?codmu $\mathrm{n}=353580>$. Acesso em: 03 jul. 2016.

Lapponi, J. C. 2007. Projetos de investimento na empresa. Editora Elsevier, Rio de Janeiro, RJ, Brasil. 
Ministério da Agricultura, Pecuária e Abastecimento [MAPA]. 2016. Citrus. Disponível em: $<$ http://www.agricultura.gov.br/vegetal/culturas/citr us>. Acesso em: 09 jun. 2016.

Nascimento, S.V. 2010. Engenharia econômica: Técnica de avaliação e seleção de projetos de investimentos. Editora Ciência Moderna, Rio de Janeiro, RJ, Brasil. Neves, M.F.; Lopes, F.F.; Trombin, V. G.; Amaro, A.A.; Neves, E.M.; Jank, M.S. 2007. Caminhos para a citricultura: Uma agenda para manter a liderança mundial. Editora Atlas, São Paulo, SP, Brasil.

Organização das Nações Unidas para a Alimentação e Agricultura [FAO]. 2016. FAO discute demanda mundial por alimentos. Disponível em:

<https://www.fao.org.br/FAOddma.asp>. Acesso em: 06 jun. 2016.

Organização para a Cooperação e Desenvolvimento Econômico [OCDE-FAO]. 2015. Perspectivas agrícolas 2015-2024. Disponível em: <https://www.fao.org.br/download/PA20142015CB .pdf $>$. Acesso em: 07 jun. 2016.

Porto, G. 2016. Após admitirem cartel, indústrias de suco de laranja pagarão R $\$ 301$ milhões ao Cade. Disponível em:

$<$ http:/ / economia.estadao.com.br/noticias/geral,aposadmitirem-cartel-industrias-de-suco-de-laranjapagarao-r-301-milhoes-ao-cade,10000090237>. Aceso em: 25 nov. 2016.

Receita Federal do Brasil. 2001. Instrução Normativa SRF N. 83, de 11 de outubro de 2001. Dispõe sobre a tributação dos resultados da atividade rural das pessoas físicas. Diário Oficial da União, Brasília, 16 out 2001. Seção 1, p. 13.

Receita Federal do Brasil. 2016. Imposto sobre a renda das pessoas físicas. Disponível em: $<$ http://idg.receita.fazenda.gov.br/acessorapido/tributos/irpf-imposto-de-renda-pessoafisica>. Acesso em: 19 set 2016

Reis, J.G.; Aragão, T.R. 2015. Viabilidade econômica da apicultura no município de Botucatu SP. Revista iPecege, 1(3): 26-35.

Silva, E.L., Ferreira, M.A.M; Monteiro, D.A.A. 2011. Viabilidade financeira da produção de feijão em sistema automatizado de irrigação por mini aspersão. Organizações Rurais \& Agroindustriais - Revista Eletrônica de Administração da UFLA 13(2):290-302.

Simões, D.; Cabral, A.C.; Oliveira, P.A. 2015.

Citriculture economic and financial evaluation under conditions of uncertainty. Revista Brasileira de Fruticultura 37(4): 859-869.

Sistema IBGE de Recuperação Automática [SIDRA]. 2016. Produção Agrícola Municipal 2015. Disponível em:

<http://www.sidra.ibge.gov.br/bda/pesquisas/pam/ $>$. Acesso em: 09 jun. 2016.

Sousa, T. R., Silva, A.C., Faria, R.Q; Silva Neto, S.P. 2013. Viabilidade econômica de cultivo da sucessão soja milho, em áreas próprias e arrendadas. XII SEMINÁRIO NACIONAL DE MILHO SAFRINHA, 12., 2013, Dourados. Estabilidade e produtividade: anuais. Disponível em:<http://www.alice.cnptia.embrapa.br/handle/doc /976574>. Acesso em: 08 nov. 2016. 